\title{
WHEN ARE YOU MOST LIKE YOUR SELF?
}

\author{
GLenN D’CRUZ
}

What is the 'self? Is it a category of identity, a state of being, an object of contemplation? Is the self another name for soul, psyche, spirit, mind or body? And what gives us our 'sense of self'? DNA? Ideology? God? These vexed questions continue to occupy the minds of scholars and artists in a variety of disciplines and creative practices, for the 'self' is a key term of distinction — one that confers us with a unique sense of identity.

The terms 'persona' and 'self' are enmeshed; they are mutually constitutive since the presentation of a public self or persona necessarily implies a private self, or, at the very least, something that is concealed by the construction of a persona. If the term 'persona' refers to some kind of social mask or performance, what lies beneath the mask? What entity controls or directs the presentation of public personae? Whether we accept or reject the existence of a core, or essential self, we are compelled to act as though we possess a sense of self even if this self is persistently under siege.

Today, more than ever, most people find themselves living part-time lives in part-time worlds, each with their own particular regulations and expectations. In other words, we perform multiple roles - parent, worker, lover, mentor, friend, hobbyist - and adopt a series of personae to cope with the varying demands of each social performance.

But how do we prioritize different roles when they clash? Does the role of parent trump the role of worker? Is there some 'core' self that negotiates the demands of different roles and personae? Can we accept our multiple identities or do we feel we can only be one identity at any one time? More importantly, is it possible to make a distinction between role identities, social personae and authentic self?

This exhibition investigates whether there are places and activities that people consider more private, and more authentic than others. It also seeks to discover how people actually talk about their 'authentic' selves without recourse to academic theorization or speculation.

The simple question, 'when do you feel most like yourself?' acted as a prompt for the artists appearing in this exhibition to produce works connected to the themes outlined above. The pieces on display cover as wide range of mediums, and explore a multiplicity of themes that are perhaps best captured in the compound words that contain the term 'self'

$$
\begin{aligned}
& \text { self-worth, self-indulgence, self-esteem, self-hatred, self-accomplishment, self- } \\
& \text { discovery, self-obsession, self-pity, self-service, self-knowledge }
\end{aligned}
$$

It is becoming increasingly difficult to make a meaningful distinction between private and public life. Indeed, the blurring of this divide is a key feature of contemporary society, and one that produces profound political consequences. As preparation for my own contribution to this exhibition, I posed the question, 'when do you feel most like yourself' to my family and friends. While I received a wide range of responses to this question, I detected certain commonalities in the answers proffered by my subjects. First, very few people questioned the 
category of 'the self' - it is clear that most people felt 'the self' to be 'self-evident'. Second, they associated the self with authenticity and liberation, responding that they felt most like themselves when free from the constraints of public life. Many people I spoke to claimed to be most like themselves at home in the company of trusted family and friends. It seems people are only too aware of the need to adopt some kind of public persona at work; however, some expressed a great deal of anxiety within the home because they feel compelled to adopt a persona in order to keep the peace with those closest to themselves. So, the people I spoke to generally experience the requirement to adopt different personae, in both private and public life, as a form of performance anxiety, and therefore take refuge in what the sociologist Erving Goffman called 'back stage' areas (Goffman 126) — that is, those sites where we don't feel the inquiring, critical gaze of an audience. One respondent, a close friend, said he felt most like himself when he was in my company because he didn't have to perform a 'politically correct' version of himself to his wife and kids. I didn't know whether to feel flattered or appalled. Another friend, a confirmed contrarian, responded that he felt like a different person with each person he encounters since each person brings out different aspects of his personality.

We hope that these works give you pause for thought, and generate debate and discussion about the relationships between selves and personae. 